\title{
Successful Health Information Technology Implementation Requires Practice and Health Care System Transformation
}

\author{
Carlos Roberto Jaén, MD, PbD, FAAFP
}

Departments of Family \& Community Medicine, and Epidemiology \& Biostatistics Research to Advance Community Health (ReACH) Center, University of Texas Health Science Center at San Antonio; and University of Texas School of Public Health, San Antonio Regional Campus; San Antonio, Texas

Ann Fam Med 2011;9:388-389. doi:10.1370/afm.1307.

$\mathrm{T}$ The complexity of primary care is increasingly recognized and documented. ${ }^{1}$

The inputs and outputs of primary care encounters require considerable additional time beyond the face-to-face time of patient encounters. ${ }^{2}$

The promises of health information technology (HIT), meaningful use, electronic prescribing, and other policy approaches are thwarted by current incentives built into primary care reimbursement, particularly the fee-for-service-only structure and its practical implementation in most practices.

Most electronic health records (EHRs) are not built to support clinical operations, particularly higher-level primary care functions that involve integrating, personalizing, and prioritizing care across a broad spectrum of opportunities that range from patients' acute concerns, management of (often multiple) chronic illnesses, prevention, mental health, family care, and often undifferentiated problems of daily living. ${ }^{3,4}$

Plug and play is not an option. ${ }^{5}$ A system that grafts on the current paper-based operations of primary care is a fantasy.

Management of chronic diseases requires timely

Conflicts of interest: author reports none.

\section{CORRESPONDING AUTHOR}

Carlos Roberto Jaén, MD, PhD, FAAFP

Department of Family \& Community Medicine

University of Texas Health Science Center at San Antonio

7703 Floyd Curl Dr

Mail Code 7794

San Antonio, TX 78229

jaen@uthscsa.edu and accurate information to guide action. Most EHRs are designed to optimize documentation of the current encounter and improve billing efficiency, not the integrated, personalized, longitudinal care of chronic illnesses or clinical operations in general. Having discrete disease data available in an EHR is necessary but not sufficient to improve care of chronic diseases. Trolling for important data necessary to optimize delivery of care is often a major barrier to delivery of quality of care. The data need to be converted to useful information.

This issue of the Annals provides 2 examples of how, to reap the benefits of HIT implementation, major adaptation and transformation are necessary in primary care practices

The article by Koopman et al provides an example of how data collected in most EHRs need to be summarized and presented in a way that allows the production of useful information so clinicians can take properly informed action to assist patients with their care of diabetes. ${ }^{6}$ The authors list 10 key clinically relevant intermediate outcome measures for diabetes care: date of last glycated hemoglobin $\left(\mathrm{HbA}_{1 \mathrm{c}}\right)$, value of last $\mathrm{HbA}_{1 \mathrm{c}}$, date of last low-density lipoprotein (LDL) cholesterol, value of last LDL cholesterol, value of last blood pressure, value of the last urine microalbumin/ creatinine ratio, date of the last foot examination, date of the last eye examination, smoking status, and use of aspirin. Every one of these data elements can prompt an action to improve care for diabetes. This approach to internal data mining and production of a diabetes dashboard provides documentation of increased efficiency and assistance in the management of this chronic disease. Constructing the dashboard requires 
the integration of technical expertise and clinical relevance, thus a transformation in the way clinicians and technical support interact and work together. The study reports a dramatic contrast in the time needed to gather this information using a dashboard vs trolling for data, a reduction on average of 4.2 minutes (from 5.5 minutes to 1.3 minutes). This found time can be used to negotiate treatment plans, to adapt to the contextual reality of the patient, and to build on the longitudinal relationship, in short, to improve the quality of the primary care provided.

Successful implementation of HIT requires deep understanding of current processes that deliver a particular function, willingness to map these processes and change them to adapt to the new systems, ${ }^{7}$ and a commitment to make the time and space needed for the key stakeholders to have the conversations that make adaptation possible. The human capital required for successful implementation is not always available inside the walls of a practice. Both technical support and change management support are needed, often from resources outside a practice.

The article by Crosson et al provides us with lessons learned from the successful implementation of electronic prescribing (e-prescribing) in 5 diverse exemplary practices. ${ }^{8}$ These lessons share a common pathway for success: (1) extensive efforts to redesign workflow with a deep understanding of the function that they are trying to deliver, (2) willingness and sufficient trust to design protocols to allow nonclinician members of the team to safely deliver prescription-related work, (3) physician champions, (4) ongoing training for team members, (5) readily available technical support, (6) targeted communication to stakeholders outside the practice (patients and pharmacists), and (7) a commitment to continuing improvement. Each of these steps requires substantial transformation of the mental models and processes that are often present in primary care practices. ${ }^{5}$

Clinicians must relinquish the axiom, "If you want something done, do it yourself." We must trust our systems, our colleagues, and our coworkers. We must enable the work and work environment to be transformed. This transformation requires respect and adaptive reserve that is not always present in primary care practices. ${ }^{4,9,10}$ Technical support is a necessary but not sufficient element of implementing HIT. The human infrastructure is essential and must be addressed, preferably a priori, to realize fully the potential benefit that HIT can bring primary care practices and their patients. ${ }^{11,12}$ This human infrastructure within the practice must be complemented by a supportive and integrated health care "neighborhood," as well as a payment structure that recognizes the substantial time frame and reinvestment in primary care necessary for it to assume its needed role in a high-functioning, highvalue, sustainable health care system. . $^{13,14}$

"Going live" is a term that is often used when implementing new information technology. Often it is not preceded by "going deep," or understanding deeply the processes and goals of the transformation needed. Both are needed for success.

To read or post commentaries in response to this article, see it online at http://www.annfammed.org/cgi/content/full/9/5/388.

Key words: Information management; electronic health records; informatics; knowledge management, practice management, medical; electronic prescribing

Submitted July 21, 2011; submitted, revised July 21, 2011; accepted July 25, 2011.

\section{References}

1. Katerndahl D, Wood R, Jaén CR. Family medicine outpatient encounters are more complex than those of cardiology and psychiatry. J Am Board Fam Med. 2011;24(1):6-15.

2. Baron RJ. What's keeping us so busy in primary care? A snapshot from one practice. N Engl J Med. 2010;362(17):1632-1636.

3. Stange KC. A science of connectedness. Ann Fam Med. 2009;7(5): 387-395.

4. Stange KC. The generalist approach. Ann Fam Med. 2009;7(3): 198-203.

5. Nutting PA, Miller WL, Crabtree BF, Jaén CR, Stewart EE, Stange KC. Initial lessons from the first national demonstration project on practice transformation to a patient-centered medical home. Ann Fam Med. 2009;7(3):254-260.

6. Koopman RJ, Kochendorfer KM, Moore JL, et al. A diabetes dashboard and physician efficiency and accuracy in accessing data needed for high-quality diabetes care. Ann Fam Med. 2011;9(5): 398-405.

7. Walker JM, Carayon P. From tasks to processes: the case for changing health information technology to improve health care. Health Aff (Millwood). 2009;28(2):467-477.

8. Crosson JC, Etz RS, Wu S, Strauss SG, Eisenman D, Bell DS. Meaningful use of electronic prescribing in 5 exemplar primary care practices. Ann Fam Med. 2011;9(5):392-397.

9. Nutting PA, Crabtree BF, Miller WL, Stewart EE, Stange $K C$, Jaén CR. Journey to the patient-centered medical home: a qualitative analysis of the experiences of practices in the National Demonstration Project. Ann Fam Med. 2010;8(Suppl 1):S45-S56, S92.

10. Miller WL, Crabtree BF, Nutting PA, Stange KC, Jaén CR. Primary care practice development: a relationship-centered approach. Ann Fam Med. 2010;8(Suppl 1):S68-S79, S92.

11. Crabtree BF, Nutting PA, Miller WL, et al. Primary care practice transformation is hard work: insights from a 15-year developmental program of research. Med Care. 2010 Sep 17 [epub ahead of print].

12. Baron RJ. Quality improvement with an electronic health record: achievable, but not automatic. Ann Intern Med. 2007;147(8):549-552.

13. Nutting PA, Crabtree BF, Miller WL, Stange KC, Stewart EE, Jaén CR. Transforming physician practices to patient-centered medical homes: lessons from the national demonstration project. Health Aff (Millwood). 2011;30(3):439-445.

14. Crabtree $B F$, Nutting $P A$, Miller WL, Stange $K C$, Stewart $E E$, Jaén CR. Summary of the National Demonstration Project and recommendations for the patient-centered medical home. Ann Fam Med. 2010;8(Suppl 1):S80-S90, S92. 